\title{
A historical overview of the United States-Mexico Border Diabetes Prevention and Control Project
}

\author{
Rita V. Diaz-Kenney, ${ }^{1}$ Rosalba Ruiz-Holguín, ${ }^{2}$ Federico G. de Cosío, ${ }^{3}$ \\ Rebeca Ramos, ${ }^{4}$ Betsy Rodríguez, ${ }^{5}$ Gloria L. Beckles, ${ }^{1}$ \\ Rodolfo Valdez, ${ }^{6}$ and Patricia E. Thompson-Reid ${ }^{1}$
}

ABSTRACT Diabetes is a serious public health problem in the border region between the United States of America and Mexico, reflecting and by some measures surpassing the extent of national diabetes burden of each country. The U.S.-Mexico Border Diabetes Prevention and Control Project, a two-phase prevalence study on type 2 diabetes and its risk factors, was conceived and developed by culturally diverse groups of people representing more than 100 government agencies and nongovernmental organizations; health care providers; and residents of 10 U.S. and Mexican border states, using a participatory approach, to address this disproportionate incidence of diabetes. This report describes the project's history, conceptualization, participatory approach, implementation, accomplishments, and challenges, and recommends a series of steps for carrying out other binational participatory projects based on lessons learned.

Key words Diabetes mellitus, type 2; risk factors; border health; international cooperation; Mexico; United States.

Division of Diabetes Translation, Centers for Disease Control and Prevention, Atlanta, Georgia, United States of America.

2 Pan American Health Organization/World Health Organization (PAHO/WHO) U.S.-Mexico Border Office, El Paso, Texas, United States of America. Send correspondence to Rosalba Ruiz-Holguín, ruizrosa@fep.paho.org

3 Pan American Health Organization/World Health Organization, Non-Communicable Disease Unit, Washington, D.C., United States of America.

4 Alliance of Border Collaboratives, El Paso, Texas, United States of America.

5 National Diabetes Education Program, Centers for Disease Control and Prevention, Atlanta, Georgia, United States of America.

6 National Office of Public Health Genomics, Centers for Disease Control and Prevention, Atlanta, Georgia, United States of America.
The border region between the United States of America and Mexico, designated in the La Paz Agreement of 1983 (1), consists of a 3 141-km area between the Gulf of Mexico and the Pacific Ocean that extends $100 \mathrm{~km}$ into the United States and Mexico north and south of the international border. Although the region comprises 44 U.S. counties and 80 Mexican municipalities, as defined by the U.S.Mexico Border Health Commission (2), the bulk of the population is concentrated in 14 sister counties-municipalities along the border. Type 2 diabetes ("diabetes") is a serious public health problem in the region, reflecting and by some measures surpassing the extent of the overall diabetes burden in Mexico and the United States, as well as worldwide, where financial and human costs of the disease are expected to double over the next 20 years (3).

\section{DIABETES BURDEN}

\section{Mexico}

By late 1999, diabetes had been recognized as a devastating public health problem in Mexico. By 2003, it was the most common cause of death. In a national cross-sectional study of 45394 participants from 400 cities, age-adjusted 
prevalence of diagnosed and undiagnosed diabetes was $8.2 \%$ ( $7.7 \%$ in women and $8.4 \%$ in men), based on Mexico's 2000 census. Half of those with diabetes had high blood pressure, $75 \%$ had a body mass index $\geq 25$ (a category classified as "overweight or obese"), and $34 \%$ were smokers. By the year 2025, an estimated 11.7 million Mexicans will have diabetes (4). Current inequalities in the provision of diabetes care could lead to poorer clinical outcomes for the majority of Mexicans diagnosed with diabetes, increasing disability and premature mortality due to diabetes-related chronic complications.

\section{United States}

As in Mexico, diabetes was widely recognized as a national public health problem in the United States by 1999. National surveillance studies such as the U.S. Centers for Disease Prevention and Control (CDC) National Health Interview Survey and the Behavioral Risk Factor Surveillance System (5) showed a steady increase in diabetes prevalence, and its impact on U.S. racial and ethnic minority populations. According to the 1999-2000 National Health and Nutrition Examination Survey IV (NHANES IV), overall prevalence of diagnosed and undiagnosed diabetes was $8.3 \%$ among persons $\geq 20$ years old, with undiagnosed cases accounting for $29 \%$ of the total (6). Based on estimates by Bar-Or et al. (7), one out of three people born in the United States in the year 2000 will develop diabetes during his/her lifetime. According to the American Diabetes Association (ADA), the cost of diabetes in the United States grew from about \$132 billion in 2002 to about $\$ 174$ billion in 2007 (a 32\% increase over five years) (8).

Among U.S. Hispanics, diabetes is projected to increase by $149 \%$ by 2050 (9), and in 2004 it was the fifth leading cause of death (and the seventh and fourth leading cause of death among nonHispanic whites and non-Hispanic blacks respectively) (10). According to CDC National Health Interview Survey data for the period 2004-2006, diabetes prevalence across U.S. Hispanic subgroups can be broken down as follows: $8.2 \%$ for Cuban Americans, $11.9 \%$ for Mexican Americans, and $12.6 \%$ for Puerto Ricans. The U.S. Hispanic population has experienced tremendous growth in the past decade, compounding the need to address the growing diabetes burden.

From 1990 to 2000, the U.S. Hispanic population grew by $57.9 \%$ (from 22.4 million to 35.3 million) while the U.S. general population increased by only $13.2 \%$. These uneven growth rates are mirrored and in most cases exceeded in U.S. border states. By the year 2000, Hispanics were the largest racial/ethnic group in New Mexico, representing $42.1 \%$ of the population. Among most U.S. Hispanic populations, including those in the border states of California, Texas, Arizona, and Nevada (11), Mexicans represent the largest group.

\section{U.S.-Mexico border region}

The high proportion of Hispanics in border areas, combined with their high incidence of diabetes versus other ethnic groups, has resulted in disproportionate diabetes prevalence in the U.S.-Mexico border region. From 2000 to 2004, diabetes mortality in U.S.-Mexico border counties and municipalities, with the exception of Tijuana, was higher than national rates in both the United States and Mexico (12). Differences in diabetes incidence by ethnic group were shown in a 2007 study in California, Texas, and Arizona that found a hospital diabetes discharge rate of 28.4/10 000 Hispanics (versus 12.4/10 000 non-Hispanics). This disparity is even more extreme in border communities, where a study by Albertorio-Diaz et al. indicated Hispanics were discharged from hospitals with a diagnosis of diabetes at a rate about $130 \%$ higher than that for non-Hispanics (13).

\section{U.S.-MEXICO DIABETES PROJECT}

\section{Overview}

To address the diabetes disease burden in the U.S.-Mexico border region, a multistage household prevalence study known as the U.S.-Mexico Border Diabetes Prevention and Control Project (1998-2010) was conducted through a partnership between the CDC, the Pan American Health Organization/World Health Organization (PAHO/WHO) U.S.-Mexico Border Office, and other U.S.-based public health agencies and the Mexican ministry of health (Secretaría de Salud). This collaboration brought together culturally diverse groups of people representing more than 100 government agencies and nongovernmental organizations; health care providers; and residents of the 10 contiguous U.S. and Mexican states-a unique partnership that was able to reach consensus on a project strategy and leverage the required resources to assess the border region's overall prevalence of diabetes and prediabetes.

This report describes the project's conceptualization, implementation, accomplishments, and challenges, and recommends a series of steps for carrying out similar binational participatory projects.

\section{Conceptualization}

The U.S.-Mexico Border Diabetes Prevention and Control Project was designed and developed based on two conceptual approaches: 1) treating the entire U.S.-Mexico border region as one epidemiologic unit, due to the fluid population movement along the border and the unique, regional disease patterns (14), and 2) involving the communities affected by diabetes in the planning, implementation, and evaluation of project activities, and engaging all stakeholders, as per the guiding principles of the National Hispanic/Latino Diabetes Initiative for Action, an effort launched in 1995 by the CDC Division of Diabetes Translation (CDC-DDT) to respond to the significant increase in the U.S. Hispanic population and its disproportionate rate of diabetes.

The core principles of the National Hispanic/Latino Diabetes Initiative for Action included promoting collaboration among strategic partners, involving affected communities in planning and implementing interventions, and using culturally and linguistically appropriate communications to address the problem of diabetes at the grassroots level. In support of those principles, the first National Hispanic/Latino Expert Consultant Group was convened in the fall of 1996 to develop a set of recommendations for more effective diabetes prevention and control needs among the Hispanic population. Using validated consensus-building methods, the National Hispanic/Latino Expert Consultant Group developed recommendations for the following areas: policy, partnership, education, funding, research and data, health systems, and public aware- 
ness. In the research/data area, the group designated two priority goals: 1) improving the dissemination of existing data on diabetes in Hispanic communities, and 2) increasing and improving Hispanic representation in data collection, surveillance, and program evaluation (15).

In response to the National Hispanic/ Latino Expert Consultant Group recommendations, the CDC-DDT approached the directors of state Diabetes Prevention and Control Programs (DPCPs) in California, Arizona, New Mexico, and Texas to find out what steps had been taken to address the diabetes burden among Hispanics in general and those in the U.S.Mexico border region in particular. (At the time, little was known about border states' specific diabetes prevalence because the sample size and methodology of the Behavioral Risk Factor Surveillance System did not allow for that type of regional assessment.) Following those discussions, having determined a crucial need for both a diabetes prevalence study in the U.S.-Mexico border region, and the engagement of the public health system on both sides of the border to address the problem, U.S. border state DPCPs invited representatives from the U.S.-Mexico Border Health Association, the CDC-DDT, and the PAHO/WHO U.S.-Mexico Border Office to participate in an exploratory meeting. PAHO's involvement in this process was critical, as PAHO personnel facilitated communication among the CDC-DDT, the Mexican ministry of health, and key stakeholders from both sides of the border (representatives from district health clinics and nongovernmental organizations). Throughout 1998, monthly conference calls and four face-to-face meetings were held to conceptualize and complete the project framework and to draft project goals and objectives.

Once consensus was reached, the CDC-DDT funded a proposal to convene a Binational Planning Committee, with staff and logistical support provided by the Mexican ministry of health. Members of the U.S.-Mexico Border Health Association-led working group engaged traditional and nontraditional partners in the planning process, and an Executive Committee, Scientific Committee, and Intervention Advisory Committee were formed. Partners included representatives from $\mathrm{PAHO}$, the Mexican ministry of health, the Departments of Health and the DPCPs of the four U.S. border states (Arizona, California, New Mexico, and Texas), border health offices, communityand faith-based organizations, local and regional ADA chapters, academia, and regional and state foundations. These partnerships led to the formation of a coalition that provided both financial and in-kind support for the project.

In 1999, the CDC and the Mexican ministry of health-joined later that year by the California Endowment Foundation, the Paso del Norte Health Foundation, and DPCPS on the U.S. side of the border-provided funds and logistical resources to carry out the project. The first step was implementation of a randomized household survey to assess diabetes prevalence, risk factors, and comorbidities in the resident population on both sides of the U.S.-Mexico border. The project's core principles reaffirmed the dual approach of 1) treating the U.S.Mexico border region as one epidemiologic unit, and 2) ensuring the project remained a true binational effort in which representatives from the United States and Mexico had an equal voice, and all recommendations and potential solutions were reached by consensus. It was also agreed that the results of the prevalence study would serve as the baseline for the project intervention phase (Phase II). This latter agreement was of special concern to members of the Mexican ministry of health, whose main priority was developing an intervention for preventing and controlling diabetes.

\section{Implementation}

Phase I (February 2001-October 2002) examined diabetes prevalence across the entire border region-the first study of this scope. Data were collected from a representative sample of the adult population of the 10 contiguous border states, using a standardized bilingual protocol, as specified in the project's Operations Manual. The objectives were to 1) determine diabetes prevalence among border residents $\geq 18$ years old, following current ADA recommendations and NHANES IV criteria, and based on fasting plasma glucose readings, and to assess glucose control by testing for glycosylated hemoglobin A1c; 2) determine the prevalence of behavioral risk factors as well as access or barriers to diabetes care, using a standard face-to-face ques- tionnaire; 3 ) assess associated risk factors for diabetes, using anthropometric and blood pressure measurements; 4) complete a quantitative analysis of the study data, and a qualitative analysis based on a literature review; and 5) develop reports for reference and recommendations based on study findings.

During the early stages of Phase I, border region partners and stakeholders said they would only support a prevalence study if the findings were used to develop community interventions to improve the health status of the population under study. Therefore, initial project activities included deliberations among staff and committee members to identify ways to ensure the development of a truly binational diabetes intervention project, culturally and linguistically appropriate for all border region areas, including both Spanish- and Englishspeaking communities. During these initial stages of Phase I it was also proposed that the intervention involve community health workers (CHWs) (known as promotores de salud in Spanish).

Phase II (2004-present) was based in part on a proposal developed by PAHO advocating the participation of two of the previously established advisory committees (the Scientific Advisory Committee and the Intervention Committee) to provide the project with technical support. The original proposal to implement a community-based research intervention was later modified by adding a cost-effectiveness component to evaluate the effectiveness of CHWs as part of the diabetes health care team. The addition of this component ultimately delayed the proposal approval process by more than one year and resulted in insufficient funding as well as an inability at the local level to complete some important project administrative requirements on time. As a result, Phase II objectives were revised to focus on 1) publishing the findings of the prevalence study conducted in Phase I, and 2) providing training on diabetes to local health care professionals and CHWs throughout the U.S.-Mexico border region, using the International Diabetes Federation Diabetes Education Modules and the Road to Health ToolKit (a primary prevention tool kit developed by the CDC National Diabetes Education Program), to strengthen diabetes-related skills and capacity in the region. 
Using the diabetes prevalence data collected in Phase I, PAHO is currently developing a curriculum for an informational forum that will bring together researchers working on chronic diseases in the border region. The objective of the forum is to provide researchers with an opportunity for networking as well as training and technical support to increase regional capacity in collecting and analyzing health-related data. The results of Phase I will also be shared with potential project advocates (border legislators, governors, health authorities, researchers, and other decision-makers) through newsletters, diabetes forums, white papers, and policy briefs.

\section{Accomplishments}

Phase I. The first phase comprised various preparatory steps, including 1) the development of guidelines for data processing and collection; 2) preparation of the adult questionnaire; 3) development of an Operations Manual that outlined the steps for implementing a household survey across the entire border region and served as a training tool for those working in the field $(16) ; 4)$ selection of the reference laboratories (the University of Missouri Diabetes Diagnostic Laboratory in Kansas City, USA, and the Nuevo León State Laboratory in Monterrey, Mexico), for analyzing blood specimens; and 5) arrangements for cross-border collection and transport of blood samples (for quality assurance).

Prevalence survey. Phase I also included the administration of a household survey to a stratified, random sample of 4027 individuals representative of the noninstitutionalized population $\geq 18$ years living in the U.S.-Mexico border region. Among the 7.5 million people in the target population, $15.7 \%$ or about 1.2 million were found to have diabetes. Of these, 500000 resided on the Mexican side of the border and about 700000 lived on the U.S. side of the border. Prevalence of prediabetes (defined as having no diabetes and fasting plasma glucose of 100-125 mg/dL) was found to be $14 \%$. When this percentage was applied to the overall border population (7.5 million), the estimated number of persons with prediabetes in the region was about 1 million (more than half of whom were women). It was also estimated that 5.3 million adults were over- weight or obese. Obese persons on the U.S. side of the border were found to have 2.8 times greater risk of developing diabetes versus persons at normal weight whereas those in Mexico had 2.2 times greater risk (17).

Communication plan. Phase I also included the development of a communication plan to prepare the targeted communities for the household survey and to increase awareness of diabetes prevention and control. Communication plan activities included publishing newspaper articles, conducting radio and television interviews, and giving presentations in local community settings and at church events. Other components of Phase I included the creation of a telecommunications network (with a contact person in each border state), the establishment of a Web site, ${ }^{7}$ and various reporting activities.

Community forum. A preliminary report of the household surveillance study was prepared and distributed during the project's first community forum, held in El Paso, Texas, in 2004. The purpose of the forum was to share project updates and information with managers, researchers, policy makers, health care professionals, and funders from the 10 U.S. and Mexican states contiguous to the border (17).

Diabetes Today training series. To strengthen local health capacity, the project conducted a training series called Comunidad en Acción (known as Diabetes Today in English). The training was designed to teach health care professionals and community members from both sides of the U.S.-Mexico border how to 1) mobilize their communities to promote diabetes prevention and control, and 2) engage community members in project activities. According to a study by Damond et al. on the Diabetes Today program, the training curriculum helped increase border communities knowledge and awareness of diabetes, and the project (17).

Phase II. The second phase of the project is currently under way and includes publishing results from the prevalence

\footnotetext{
7 http://www.fep.paho.org/eng/Technical Cooperation/Diabetes/tabid/284/language/ en-US/Default.aspx
}

study, delivering training for local health care providers and $\mathrm{CHWs}$ on diabetes care and self-management, and educating policy makers on the health needs of the border population.

Training. Seven sites along the border were selected to provide training in English and/or Spanish (as appropriate). The training targets are 1) CHWs, on the use of the CDC National Diabetes Education Program's Road to Health ToolKit (based on the results of the National Institute of Diabetes and Digestive and Kidney Diseases Diabetes Prevention Program Study), and 2) health care professionals, on diabetes care and selfmanagement (based on the curriculum developed by the International Diabetes Foundation) (18).

Diabetes forums. The objectives of the diabetes forums are to educate participants on the health needs of the border population, with specific emphasis on diabetes, to improve border region diabetes-related policies. The forums will target policy makers, health care professionals, the media, faith-based and community-based organizations, and people with diabetes and their families living in the border region.

Publications. Policy briefs and white papers have been developed by various border institutions, California State University, and the University of New Mexico Health Sciences Center. These publications will be distributed to policy makers and decision makers as well as local community leaders.

\section{DISCUSSION}

\section{Challenges and opportunities}

Funding. At the beginning of the project, the CDC-DDT did not have a mechanism to fund it. Several types of administrative arrangements were considered, based in part on their ability to accommodate the binational nature of the project. Ultimately, the CDC-DDT implemented an interagency agreement with the U.S. Department of Health and Human Services Office of International and Refugee Health (OIRH), which had a pre-existing memorandum of agreement with PAHO. The memorandum between CDC-DDT and OIRH that eventually funded the project was effective 
from fiscal year 1999-2000 through fiscal year 2003-2004. During that time, the Office of Global Health (OGH) at CDC's National Center for Chronic Disease Prevention and Health Promotion developed an umbrella cooperative agreement with PAHO. The cooperative agreement was finalized in the spring of 2005, and PAHO received funding from the OGH for a five-year project period. However, the PAHO-OGH agreement was centered on health promotion-not research-so the project could not officially begin until a new funding mechanism was identified. During this interim period, PAHO directed project resources toward preparing and analyzing the data from the diabetes prevalence study, finalizing the project's Operational Plan, and training CHWs and other community participants to prepare them for the startup of the intervention phase (Phase II).

Staffing and decision-making. The PAHO/WHO U.S.-Mexico Border Office, established in 1942 to help coordinate border health campaigns for the U.S. Public Health Service, was uniquely positioned to collaborate with the CDC-DDT to improve the accessibility and use of health care services along the border, and had a long history of responding to the health needs of the predominantly Hispanic population residing in the border region. Project staff at this office included three full-time administrators (a Binational Coordinator, a U.S. Coordinator, and an Administrative Assistant), a part-time Fiscal Assistant, and a part-time Mexican Coordinator (funded by the Mexican ministry of health). Project staff also included 10 State and Local Supervisors at each site where surveys were conducted.

As in most long-term endeavors, there was a considerable amount of project staff turnover. During Phase I, for example, there were three different National Coordinators in Mexico and the United States. In some cases, this turnover caused delays in project implementation, as new project personnel and those returning from extended leave (maternity, disability, etc.) required additional time to become fully informed and involved and to proceed with or resume project tasks and duties. These delays, in turn, increased the time required for decisionmaking by project management.

To streamline the process, an Executive Committee was established to over- see the implementation of project activities, supported by two other committees (the Scientific Committee and the Intervention Advisory Committee). Members of the two latter committees assisted with project implementation by providing recommendations to the Executive Committee through their respective chairs. These committees were instrumental in developing both the survey protocols and the intervention proposal. Therefore, any constraints resulting from the additional time required for the project's specific style of management and decision-making (which could be described as "management by committee" and "decision-making by consensus") were offset by the value added from the participation of the committee members, who represented border communities vested in the project's successful completion.

Communications. Because the project was participatory in nature, the concept of shared leadership was embraced as a basic operational principle, and the roles and responsibilities of that leadership changed depending on the nature of the tasks to be performed. The focus on equal participation created a challenge in terms of information exchange that was compounded by the use of two working languages (English in the United States and Spanish in Mexico). Maintaining open, participatory communication was one of the most challenging aspects of the project. Communicating effectively based on the criteria described above required extensive, costly, time-consuming efforts, including the translation of all e-mail, meeting minutes, and teleconferences, and the use of interpreters for face-toface meetings.

Spontaneous communication represented a unique challenge because the Binational Coordinator and other bilingual members had to serve as interpreters for committee members from both countries. This slowed committee activities and increased the time needed to reach consensus. Therefore, instantaneous translation (the use of specialized software for instant translation of spoken language into text displayed in various formats) was arranged in advance for teleconferencing and face-to-face meetings, as well as project-sponsored community forums. Although timeconsuming and costly, the speed, ease, and versatility of instantaneous transla- tion services helped build trust among partners and thus contributed to consensus building.

Project e-mail was exchanged regularly, and telephone conferences were conducted weekly, organized by the Binational and National Coordinators. Telecommunication services were sometimes problematic due to technical difficulties, especially in Mexico, where telephone lines were used by more than one telecommunications program. Frequent communication was critical to ensure that all parties received up-to-date information on project activities and to allow for early troubleshooting and sharing of recommendations to address identified challenges. A well-designed communication process was necessary to maintain connectivity among all of the partner organizations and keep them focused on project goals and objectives.

Project operations. Project field operations began in February 2001. A total of 4027 interviews were conducted and 3539 blood samples were drawn (an $87.9 \%$ completion rate). Implementing such a complex household prevalence study involved many challenges. PAHO's Binational Coordinator, along with the Mexican and U.S. Coordinators, had primary responsibility for overseeing the implementation of activities carried out in the household survey. These staff members, in collaboration with the respective committees, reviewed and approved the instruments and procedures that were developed, produced contracts to secure necessary services, finalized the survey questionnaire design and printing, supervised database development, and maintained ongoing dialogue among partners. They were also responsible for coordinating all project activities with the 10 State and Local Supervisors, and recruiting and training the interviewers for Phase I survey activities.

Cultural, logistical, and other constraints. Certain difficulties arose during home interviews. For example, in one case in the United States, interviewers had to contact five households in order to find one participant willing to participate in the survey. Following the terrorist attacks in the United States in 2001, survey fieldwork was often delayed due to general feelings of anxiety and fear, resulting in an unusually high number of residents who were either unrespon- 
sive to interview requests or uncooperative during interviews. Over time, however, as the project's communication materials informed the community about the survey, fears were allayed and a more cooperative study environment emerged.

One logistical constraint was the fact that, according to the study methodology, all project materials (e.g., manuals and questionnaires), equipment, and formats had to be the same for both countries. Fulfilling this requirement (which required sending equipment and samples to and from the United States and Mexico) often delayed project activities. Another constraint was the need to obtain approval from the institutional review boards of the different agencies involved in the study, which also caused project delays.

Capacity building. Committee members recognized that reducing the burden of diabetes in the border region required developing and maintaining a solid public health infrastructure. Therefore, the project's training and skill-building sessions for health care professionals and ancillary staff were considered an important contribution to building capacity among health care workers in the region. Centralized training for supervisors was also conducted to maintain consistency in the implementation of the household survey. Supervisors were trained in English and Spanish using the project's Operations Manual as the reference tool. The State and Local Supervisors trained all interviewers with the support of the National (United States or Mexico) Coordinator. Local training was provided in Laredo and El Paso, Texas; San Diego and Imperial, California; Yuma, Santa Cruz, and Pima, Arizona; and Deming, New Mexico, in the United States; and in Guadalupe, Sonora; Ciudad Juárez, Chihuahua; Piedras Negras, Coahuila; Ciudad Anahuac, Nuevo León; Mexicali, Baja California; and Reynosa, Tamaulipas, in Mexico.

All interviewers completed training on proper administration of anthropometric measurements and were certified (or recertified) for measuring study participants' blood pressure. Frequent staff turnover required that these training sessions be repeated, as needed, for new staff. In some cases, training updates were offered to staff already working in the field. All laboratory staff involved in the collection, analysis, or transport of project blood samples were trained by staff from the U.S. reference laboratory in Kansas City.

\section{Conclusion}

The U.S.-Mexico Border Diabetes Prevention and Control Project was a complex, binational project involving multiple partners and funding sources. Many points of view had to be considered and reconciled. The availability of resources and infrastructure was a challenge that limited the full implementation of the project as originally conceived. In addition, the project faced unanticipated logistical problems. Many of these problems were resolved satisfactorily, while others resulted in eventual changes to the scope of the project.

The active involvement of representatives of the entire diabetes public health system in the U.S.-Mexico border region made the project unique and helped garner financial and in-kind support from numerous partners and collaborators. Binational cooperation was maintained in all project communications, creating an environment in which everyone felt vested in project activities.

The project was the first of its kind to successfully conduct a prevalence study along the entire border of two adjoining nations and therefore can serve as a model for future binational efforts and provide practical insights on involving affected populations in applied community research. In addition, the findings from the diabetes prevalence study conducted in Phase I could help inform the additional strategic planning that will be required to address the disproportionate burden of diabetes in the region.

\section{Recommendations}

Based on lessons learned from the project, the authors recommend the following points be considered by future investigators working along the U.S.Mexico border or in similar regions:

1. In instances where residents have similar socioeconomic and cultural characteristics, treat the region as one epidemiologic unit.

2. Make binational and bilingual operational and scientific protocols avail- able to provide standard guidance on scientific data collection and analyses across the region.

3. Work to strengthen the infrastructure and capacity of all partner entities at the local and regional level.

4. Use prevalence study findings to inform future strategic planning efforts to improve the health of residents in the region.

5. Incorporate prevalence findings in the evaluation of intervention strategies and programs.

6. Use a participatory research process that involves community members and gives them a sense of ownership of the project.

7. Create committees with a diverse membership of representatives and subject matter experts who can work together to achieve project goals and objectives.

8. Facilitate the development of culturally and linguistically appropriate project materials and make them available for use locally.

9. Obtain funding from multiple sources at the local, state, and federal level, and use one fiduciary agent independent of municipalities at each level to oversee funds management.

10. Investigate beforehand the legal issues related to sharing epidemiologic information, transporting biologic samples, and using federal and state dollars for health-related activities across the border.

11. Allocate sufficient funds for administrative and technical support, including translation services.

12. Recognize the potential complexity of institutional review board requirements for multiple performance sites in multiple countries to protect human research participants from research risks, and carefully plan for and implement the necessary processes and procedures for timely fulfillment of those requirements.

Project participants. The following institutions contributed to and supported the U.S.-Mexico Border Diabetes Prevention and Control Project:

Mexico: Asociación de Diabetes de Ciudad Juárez; Asociación de Diabetes de Nogales, Sonora; Asociación Mexicana de Diabetes, capítulo de Chihuahua; Centro Nacional de Vigilancia Epide- 
miológica y Control de Enfermedades de México; Jurisdicciones Sanitarias de los Estados Fronterizos; Laboratorio Estatal de Monterrey; Programa de Salud del Adulto y del Anciano del Estado de Baja California; Programa de Salud del Adulto y del Anciano del Estado de Chihuahua; Programa de Salud del Adulto y del Anciano del Estado de Coahuila; Programa de Salud del Adulto y del Anciano del Estado de Nuevo León; Programa de Salud del Adulto y del Anciano del Estado de Sonora; Programa de Salud del Adulto y del Anciano del Estado de Tamaulipas; Secretaría de Salud de México; Universidad Autónoma de Ciudad Juárez.

United States: American Institute of Research; Arizona Border Health Office; Arizona Department of Health Services;
Arizona Diabetes Control Program; Border Health Foundation; Border Health Research; California Department of Health Services; California Diabetes Control Program; Center for Border Health Research; Centers for Disease Control and Prevention; College of Public Health of the University of Arizona; County of San Diego Public Health Laboratory; Doña Ana County Community College; El Paso Diabetes Association; Gateway Community Health Center; Health Resources and Services Administration; Home Choice Nurses; Local Border Health Departments; National Diabetes Today Training Center Office of International Health and Human Services; New Mexico Department of Health; New Mexico Diabetes Control Program; New Mexico State University at Las Cruces; Pan American Health Or-

\section{REFERENCES}

1. U.S. Department of State. Environmental Cooperation: Agreement between the United States of America and Mexico. August 14. TIAS no. 10827. United States and treaties and other international agreements. Washington, D.C.: Government Printing Office; 1983. Available from: http://www.epa.gov/ usmexicoborder/docs/LaPazAgreement.pdf. Accessed 29 January 2010.

2. United States-Mexico Border Health Commission. The U.S.-Mexico border region. El Paso, Texas: USMBHC; 2010. Available from: http:/ / www.borderhealth.org/border region.php. Accessed 29 January 2010.

3. U.S. Centers for Disease Control and Prevention, Division of Diabetes Translation. National Hispanic/Latino Expert Consultant Group Recommendations [page on the Internet]. Atlanta, GA: CDC; 1998. Available from: http://www.cdc.gov/diabetes/pubs/nhlRe commendations.htm. Accessed 29 February 2010.

4. Aguilar-Salinas CA, Velazquez Monroy O, Gómez-Pérez FJ, Gonzalez Chávez A, Esqueda AL, Molinas Cuevas V, et al. Characteristics of patients with type 2 diabetes in Mexico: results from a large populationbased nationwide survey. Diabetes Care. 2003;26(7):2021-6.

5. Mokdad AH, Ford ES, Bowman BA, Nelson DE, Engelgau MM, Vinicor F, et al. Diabetes trends in the US: 1990-1998. Diabetes Care; 2000;23(9):1278-83.

6. U.S. Centers for Disease Control and Prevention. Prevalence of diabetes and impaired fasting glucose in adults-United States,
1999-2000. MMWR Morb Mortal Wkly Rep. 2003;52(35): 833-7.

7. Bar-Or O, Foreyt J, Bouchard C, Brownell KD, Dietz WH, Ravussin E, et al. Physical activity, genetic, and nutritional considerations in childhood weight management. Med Sci Sports Exerc. 1998;30(1):2-10.

8. Songer TJ, Ettaro L. Economics of Diabetes Project Panel. Estimates of the economic cost of diabetes mellitus in the United States, by study. Atlanta, GA: Centers for Disease Control and Prevention, National Center for Chronic Disease Prevention and Promotion, Division of Diabetes; 1998. Available from: http://www. cdc.gov/diabetes/pubs/costs/ tables.htm\#table2. Accessed 29 January 2010.

9. Engelgau MM, Geiss LS, Saaddine JB, Boyle JP, Benjamin SM, Gregg EW, et al. The evolving diabetes burden in the United States. Ann Intern Med. 2004;140(11):945-50.

10. National Institute of Diabetes and Digestive and Kidney Diseases. National diabetes statistics, 2007. Bethesda, MD: U.S. Department of Health and Human Services, National Institutes of Health; 2008.

11. Guzman B. The Hispanic Population: Census 2000 brief. Washington, D.C.: U.S. Census Bureau; 2001. Available from: http://www. census.gov/prod/2001pubs/c2kbr01-3.pdf. Accessed 29 February 2010.

12. Pan American Health Organization. Mortality profiles of the sister communities on the United States-Mexico border-1992-1994. Washington, D.C.: PAHO; 1999.

13. Albertorio-Diaz JR, Notzon FC, RodriguezLainz A. Diabetes hospitalization at the U.S.- ganization; Paso del Norte Health Foundation; Primus Corporation; Project Concern International; R.E. Thomason Hospital, El Paso, Texas; Rio Grande Council of Governments; Southwest Arizona Health Education; Texas Department of State Health Services; Texas Diabetes Control Program; The California Endowment; United States Department of Health and Human Services; University of Missouri, School of Medicine; University of Texas at Houston School of Public Health at El Paso; U.S.-Mexico Border Health Association; Western Arizona Area Health Education Center.

Disclaimer. The findings and conclusions in this report are those of the authors and do not necessarily represent the official position of the U.S. Centers for Disease Control and Prevention.
Mexico border. Prev Chron Dis. 2007;4(2): A28. Available from: www.cdc.gov/pcd/ issues/2007/apr/06_0073.htm. Accessed 29 February 2010.

14. Brandon JE, Crespin FH, Levy C, Reyna DM Border health issues. In: Bruhn JG, Brandon JE, eds. Border health: challenges along the U.S.-Mexico border. New York, N.Y.: Garland Press.

15. Arévalo J, Borges R. Prevalence of disabilities: manual of home surveys. Washington, D.C. Pan American Health Organization; 1990.

16. U.S.-Mexico Border Diabetes Prevention and Control Project. First report of results. El Paso, Texas: Pan American Health Organization/World Health Organization; 2004. Available from: http://www.infofrontera. org/lildbi/docsonline/fep002607. Accessed 29 February 2010.

17. Damond M, Winters A, Jack L Jr, Cropper D, Londoño M, Stoddard R. Mobilizing communities: local applications of the Diabetes Today national training center project. J Public Health Manag Pract. 2003;(Suppl):S15-8.

18. International Diabetes Federation. International curriculum for diabetes health professional education. Brussels: IDF; 2009. Available from: http://www.idf.org/internationaleducation-curriculum. Accessed 29 February 2010.

Manuscript received on 6 May 2010. Revised version accepted for publication on 24 August 2010. 
RESUMEN La diabetes es un problema grave de salud pública en la zona fronteriza entre México y los Estados Unidos, que refleja y, en cierta medida, sobrepasa la magnitud de la carga nacional de la diabetes de cada país. El Proyecto de Prevención y Control de

Perspectiva histórica del Proyecto de Prevención y Control de la Diabetes en la Frontera México-Estados Unidos

Palabras clave la Diabetes en la Frontera México-Estados Unidos, un estudio de prevalencia de dos fases sobre la diabetes tipo 2 y sus factores de riesgo, se ideó y elaboró por grupos de personas culturalmente diversos que representaban a más de 100 organismos estatales y organizaciones no gubernamentales, profesionales de salud y residentes de 10 estados de la zona fronteriza entre México y los Estados Unidos, con la aplicación de un enfoque participativo, a fin de estudiar esta desproporcionada incidencia de diabetes. En este informe se describen la historia, la conceptualización, el enfoque participativo, la ejecución, los logros y los retos del proyecto, y se recomienda una serie de pasos para la realización de otros proyectos participativos binacionales, a partir de las lecciones aprendidas.

Diabetes mellitus tipo 2; factores de riesgo; salud fronteriza; cooperación internacional; México; Estados Unidos. 